\title{
DESEMPENHO DE HÍBRIDOS DE MILHO COM CICLOS CONTRASTANTES EM FUNÇÃO DA DESFOLHA E DA POPULAÇÃO DE PLANTAS
} \author{
Clair Rampazzo ${ }^{3,4}$ \\ ${ }_{2}^{1}$ Depto. de Fitotecnia - CAV/UDESC, C.P. 281 - CEP: 88520-000 - Lages, SC. \\ ${ }^{2}$ Pós-Graduando do Depto. de Solos - CAV/UDESC. \\ ${ }^{3}$ Graduandos em Agronomia - CAV/UDESC. \\ ${ }_{5}^{4}$ Bolsista CNPq. \\ ${ }^{5}$ Bolsista CAPES. \\ *Autor correspondente<a2Is@cav.udesc.br>
}

Luís Sangoi ${ }^{1,4 *}$; Milton Luiz de Almeida ${ }^{1,4}$; Vanderlei Adilson Lech ${ }^{2,5}$; Luiz Carlos Gracietti ${ }^{3,4}$;

RESUMO: A velocidade com que o milho se desenvolve da emergência até a antese pode interferir na determinação de práticas de manejo importantes para a cultura, bem como na sua capacidade de tolerar estresses na floração. Este trabalho foi conduzido objetivando determinar a relação existente entre precocidade e a resposta de híbridos de milho ao incremento na população de plantas e à redução de área foliar. 0 experimento foi conduzido em Lages, SC, durante o ano agrícola de 1999/2000. Foram testados três híbridos contrastantes em exigência calórica para florescimento: P32R21, super precoce; Premium, precoce; e C333B, tardio. Foram estudadas quatro densidades: 25.000, 50.000, 75.000 e 100.000 pl ha-1. Os genótipos foram avaliados com sua área foliar intacta e com remoção de metade das folhas verdes presentes durante 0 espigamento. A população de plantas necessária para maximizar o rendimento de grãos foi tanto menor quanto mais tardio o híbrido. O híbrido superprecoce P32R21 apresentou menor área foliar e maior rendimento de grãos do que o tardio C333B, tanto nas parcelas em que as folhas foram mantidas intactas quanto nas desfolhadas. Isto ocorreu devido a maior capacidade do P32R21 de remobilizar as reservas do colmo para atender à demanda exercida pelos grãos.

Palavras-chave: Zea mays, fonte, dreno, remobilização

\section{PERFORMANCE OF CONTRASTING CYCLE MAIZE HYBRIDS AS AFFECTED BY DEFOLIATION AND PLANT POPULATION}

\begin{abstract}
The speed of maize development from emergence to anthesis may affect the response of the crop to important management practices and interfere on the ability of corn to cope with stresses at flowering. This experiment was conducted objecting to evaluate the relationship between earliness and maize response to the increase in plant population and defoliation. The trial was performed in Lages, SC, Brazil, during 1999/ 2000. Three contrasting hybrids in terms of heat unit requirement to reach flowering were tested: P32R21, very early; Premium, early; and C333B, late. These hybrids were submitted to four plant populations: 25,000, $50,000,75,000$ and 100,000 $\mathrm{pl} \mathrm{ha}^{-1}$. Genotypes were evaluated with full leaf area and removing half of their green leaves at silking. The plant population required to maximize grain yield was lower for late than for early hybrids. Hybrid P32R21 presented a smaller leaf area and greater grain yield than C333B, regardless of defoliation. This was accomplished due to P32R21 higher capacity to mobilize its stem stored compounds to match the sink demand of the grain.
\end{abstract}

Key words: Zea mays, source, sink, remobilization

\section{INTRODUÇÃO}

Os híbridos e variedades cultivadas de milho disponíveis no mercado são classificados quanto a duração do seu ciclo em três categorias principais: superprecoces, precoces e tardios. Esta classificação é feita considerando o número de unidades de calor (UC) que cada genótipo requer para florescer (Sangoi, 1993; Fepagro/Emater/Fecotrigo, 1998). Os materiais genéticos tardios necessitam de maior soma calórica para atingirem o pendoamento-espigamento do que os materiais precoces. Híbridos mais exigentes em UC para florescerem possuem em seu genoma maior participação de linhagens tropicais. Assim, a precocidade tem sido acentuada pelos programas de melhoramento de milho através da incorporação de linhagens oriundas de germoplasma temperado (Fischer \& Palmer, 1984).

As alterações fenológicas que ocorrem dentro da planta podem ter influência sobre características morfológicas e fisiológicas da cultura (Mundstock, 1999). Isto terá reflexo na definição de práticas culturais a serem adotadas na lavoura, bem como na tolerância do milho a estresses bióticos e abióticos. 
De maneira geral, quanto maior a precocidade de um material, menor é o seu número de folhas expandidas na antese, menor a sua área foliar e mais reduzida é a estatura final da planta (Almeida et al., 2000). Tais características fazem com que a competição intra-específica pelos recursos ambientais seja potencialmente menor nos materiais de ciclo curto. Com isto, para maximizar o rendimento de grãos destes genótipos necessita-se, teoricamente, de um maior número de indivíduos por área (Sangoi, 2000).

Por outro lado, a maior velocidade de crescimento vegetativo e de desenvolvimento das inflorescências masculina e feminina faz com que os materiais superprecoces e precoces sejam geralmente mais exigentes em condições edáficas e climáticas favoráveis para o adequado desenvolvimento das espigas (Fancelli \& Dourado Neto, 2000). Estes materiais dispõem de menos tempo para se recuperar de restrições ambientais impostas ao aparato fotossintético da planta nas fases de pré-floração, floração e início de enchimento de grãos. Assim, prejuízos impostos à fonte produtora de carboidratos podem reduzir o rendimento de grãos de materiais precoces mais drasticamente do que dos tardios (Tollenaar \& Dwyer, 1999).

Este trabalho foi conduzido com os seguintes objetivos: relacionar a soma calórica necessária para 0 florescimento com características morfológicas e fisiológicas de híbridos de milho; verificar a relação existente entre exigência em unidades de calor para o florescimento e o potencial de resposta do rendimento de grãos ao incremento da população; e identificar se há associação entre precocidade e intensidade dos prejuízos ao rendimento de grãos promovidos pela redução de área foliar no florescimento.

\section{MATERIAL E MÉTODOS}

O experimento foi conduzido em Lages, SC, durante o ano agrícola de 1999/2000. O município de Lages está localizado a $27^{\circ} 52^{\prime} \mathrm{S}$ e $50^{\circ} 18^{\prime} \mathrm{O}$, numa altitude de $930 \mathrm{~m}$ acima do nível do mar. O clima da região é do tipo $\mathrm{Cfb}$, de acordo com a classificação de Köppen, apresentando temperaturas amenas no verão, invernos frios e precipitação pluviométrica bem distribuída o ano todo. O solo da área experimental é um NITOSSOLO VERMELHO (Embrapa-Centro Nacional de Pesquisa de Solos, 1999).

$O$ delineamento experimental utilizado foi 0 de blocos casualizados, dispostos em parcelas subsubdivididas. Na parcela principal foram testados três híbridos contrastantes em exigência calórica para o florescimento: P32R21, superprecoce; Premium, precoce; e C333B, tardio. Os híbridos testados exigem 790,860 e 970 UC para alcançarem o pendoamentoespigamento, respectivamente (Epagri, 2000). Cada híbrido foi alocado, nas subparcelas, com quatro populações equivalentes a 25000, 50000, 75000 e
100000 plantas por hectare. Em cada população, os híbridos foram avaliados, nas sub-subparcelas, com sua área foliar intacta e com a remoção de metade das folhas presentes no espigamento. Nas parcelas desfolhadas, removeu-se integralmente a lâmina das folhas na fração intermediária do colmo, nas quais se localizavam as espigas da planta. Assim, se as plantas de uma determinada parcela apresentavam 14 folhas verdes, removeu-se três folhas acima da espiga superior, a folha índice e três folhas abaixo da mesma. Tais folhas foram removidas quando $50 \%$ das plantas apresentavam-se espigadas (estilo-estigmas visíveis). Cada subsubparcela foi constituída por cinco linhas de sete metros de comprimento. A linha dois foi utilizada para avaliar a distribuição e acúmulo de massa seca nas diferentes frações da planta. A linha quatro foi empregada para estimar o rendimento de grãos e demais características agronômicas avaliadas no experimento. As demais linhas foram consideradas como bordadura.

O experimento foi conduzido no sistema de semeadura direta, sobre uma cobertura morta de aveia preta, a qual foi dessecada mediante a aplicação de $1.400 \mathrm{~g}$ de i.a. do herbicida glifosate, 15 dias antes da semeadura do milho. Foram aplicados, na base, $20 \mathrm{~kg}$ de $\mathrm{N}, 70 \mathrm{~kg}$ de $\mathrm{P}_{2} \mathrm{O}_{5}$ e $100 \mathrm{~kg}$ de $\mathrm{K}_{2} \mathrm{O}$. Em cobertura aplicou-se mais $80 \mathrm{~kg}$ de $\mathrm{N}$ quando as plantas apresentavam cinco folhas expandidas. A adubação foi feita considerando os valores de reposição sugeridos pela Comissão de Fertilidade do Solo -RS/SC (1995), para lavouras de milho com perspectivas de obtenção de rendimento de grãos superiores a $6.000 \mathrm{~kg} \mathrm{ha}^{-1}$.

O ensaio foi instalado em 11/11/1999, utilizandose semeadoras manuais e depositando-se três sementes por cova, com espaçamento entre linhas de $75 \mathrm{~cm}$. $O$ espaçamento entre covas adjacentes dentro da linha foi de $53,3,26,6,17,8$ e $13,3 \mathrm{~cm}$, respectivamente, para as densidades de $25.000,50.000,75.000$ e 100.000 plantas por hectare.

Uma combinação de atrazina (1.400 g i.a. por hectare) e metolachlor (2.100 g i.a. por hectare) foi aspergida sobre a superfície do solo logo após a semeadura para o controle pré-emergente de plantas daninhas. Sempre que necessário, efetuou-se controle mecânico pós-emergente das invasoras de forma que as mesmas não interferissem no desenvolvimento adequado da cultura. No estádio V4, quatro folhas totalmente expandidas (Ritchie \& Hanway, 1993), efetuou-se o desbaste para ajustar a população aos valores definidos em cada tratamento.

Durante os estádios V4 e V8 da cultura, as extremidades da quarta e oitava folhas de cinco plantas escolhidas ao acaso em cada subparcela não desfolhada foram marcadas com tinta não lavável. Tais plantas foram utilizadas para a determinação do número de folhas totais de cada híbrido e para a estimativa da área foliar. Estas variáveis foram determinadas quando as plantas marcadas se encontravam espigadas. A área foliar foi 
estimada segundo metodologia apresentada por Tollenaar (1992), aplicando a expressão: $A F=C \times L \times 0,75$, onde $C$ e $L$ representam, respectivamente, comprimento e largura média em centímetros de cada folha.

$O$ intervalo entre antese e espigamento foi calculado computando-se a diferença entre o número de dias necessários para que $50 \%$ e $90 \%$ das plantas apresentassem deiscência de pólen e estigmas visíveis, respectivamente.

Cinco plantas foram coletadas ao acaso no florescimento (pelo menos $50 \%$ das plantas em antese) e no dia da colheita de cada híbrido. Estas plantas foram dissecadas, separando-se em embalagens distintas colmos e pendões, folhas e espigas. O material foi colocado em estufa a $60^{\circ} \mathrm{C}$ até a obtenção de massa seca constante. Com os valores de massa seca alocados às diferentes estruturas da planta, calculou-se 0 rendimento biológico (fitomassa total da planta), índice de colheita (fração da massa seca total concentrada nos grãos) e índice de remobilização (parâmetro indicativo da percentagem de reservas do colmo remobilizada aos grãos durante o período de enchimento dos mesmos). $O$ índice de remobilização foi calculado utilizando-se a expressão, apresentada por Rajcan \& Tollenaar (1999): $\mathrm{I} . \mathrm{R}=(\mathrm{MSE}-\mathrm{MSC}) / \mathrm{MSE} \times 100$, em que MSE representa a massa seca de colmo e pendão no espigamento e MSC a massa seca de colmos e pendões na colheita.

A colheita do milho foi feita manualmente, quando todas as folhas da planta estavam senescidas. Momentos antes da colheita, efetuou-se a estimativa da percentagem de plantas acamadas, quebradas e do diâmetro médio de colmo. As plantas foram consideradas acamadas quando o ângulo entre a base do colmo e o nível do solo foi inferior a $45^{\circ}$. Foram considerados quebrados os colmos que apresentaram ruptura significativa no seu tecido de sustentação abaixo do ponto de inserção da espiga superior. $O$ diâmetro de colmo foi medido com um paquímetro na metade do primeiro entre-nó expandido do colmo de cinco plantas escolhidas ao acaso em cada sub-subparcela. Após a colheita, as espigas foram despalhadas, trilhadas e os grãos colocados em estufa a $60^{\circ} \mathrm{C}$ até a obtenção de peso constante. Posteriormente foi determinada a massa dos grãos e os valores obtidos convertidos para uma área equivalente a 1,0 ha e expressos na umidade de $13 \%$.

Os dados foram avaliados estatisticamente através de análise de variância e os efeitos dos tratamentos foram testados através do teste $F$. Os valores de $F$ para efeitos principais e interações foram considerados significativos ao nível de $5 \%(P<0,05)$. Quando atingida significância estatística, a comparação entre médias foi realizada através do teste de Duncan para os fatores qualitativos, ao nível de $5 \%$ de probabilidade. Para os fatores quantitativos, utilizou-se análise de regressão, testando-se os modelos linear e quadrático. A densidade ótima para maximizar o rendimento de grãos dos híbridos que responderam quadraticamente ao incremento da população foi calculada derivando-se a equação calculada e igualandoa a zero.

\section{RESULTADOS E DISCUSSÃO}

O ano agrícola de 1999/2000 apresentou um regime de chuvas bem distribuídas ao longo de toda a estação de crescimento da cultura, não havendo períodos significativos de estiagem que pudessem comprometer crescimento e desenvolvimento das plantas. Tal fato, associado a alta fertilidade da área experimental, propiciaram a obtenção de rendimentos de grãos elevados, superiores a $5.000 \mathrm{~kg} \mathrm{ha}^{-1}$, em todos os tratamentos avaliados no experimento.

O rendimento de grãos dos genótipos testados foi influenciado significativamente pelas interações entre híbrido x população e híbrido $x$ nível de desfolha (TABELA 1). $O$ aumento na densidade de 25.000 para 100.000 plantas por hectare incrementou linearmente o rendimento de grãos do híbrido superprecoce P32R21 (Figura 1). Para cada adição de 10.000 plantas por hectare houve um incremento de $310 \mathrm{~kg} \mathrm{ha}^{-1}$ no rendimento de grãos deste híbrido. O rendimento dos híbridos Premium e C333B respondeu de forma quadrática ao incremento da população. As densidades ótimas para maximizar 0 rendimento destes materiais foram de 95.520 e 60.730 plantas por hectare, respectivamente.

A interação verificada entre ciclo do híbrido e população de plantas necessária para maximizar o rendimento de grãos está de acordo com as observações feitas por Olson \& Sanders (1988), Silva (1992) e Sangoi (2000). Segundo estes autores, há uma relação inversa entre a exigência calórica do genótipo para florescer e número de indivíduos requeridos para maximizar a exploração do ambiente. Neste sentido, materiais com soma calórica baixa para pendoar, tais como o P32R21, têm maior potencial de incremento no rendimento de grãos com o uso de estandes mais adensados do que materiais que requerem somas calóricas elevadas para florescer, tais como o C333B.

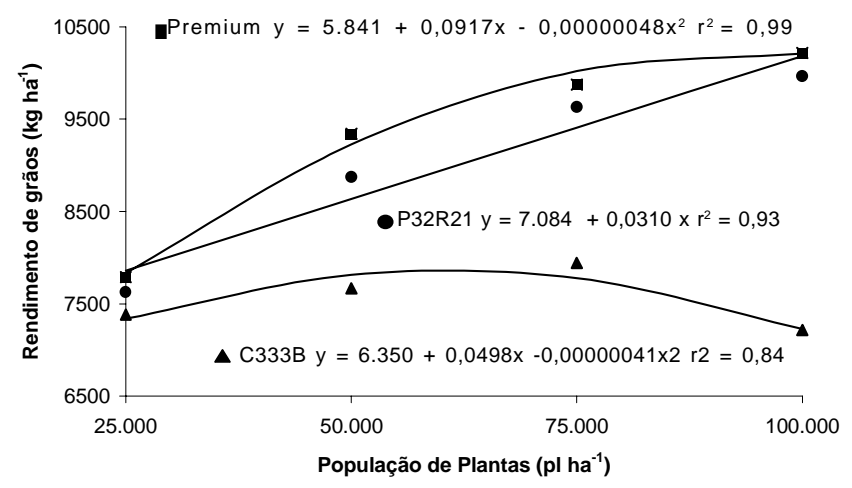

Figura 1 - Resposta de rendimento de grãos de híbridos de milho de ciclos contrastantes ao aumento de densidade de semeadura, na média de dois niveis de desfolha, Lages, SC, 1999/2000. 
TABELA 1 - Quadrados médios obtidos na análise de variância efetuada para as principais variáveis analisadas no trabalho.

\begin{tabular}{|c|c|c|c|c|c|c|c|c|c|}
\hline $\begin{array}{l}\text { Fonte de } \\
\text { Variação }\end{array}$ & G.L. & $\begin{array}{l}\text { Rendim. } \\
\text { grãos }\end{array}$ & $\begin{array}{c}\text { Acam. + } \\
\text { quebra }\end{array}$ & $\begin{array}{l}\text { Índice } \\
\text { Colheita }\end{array}$ & $\begin{array}{c}\text { Índice } \\
\text { remobiliz }\end{array}$ & G.L & $\begin{array}{l}\text { Área } \\
\text { foliar }\end{array}$ & $\begin{array}{l}\text { Folhas } \\
\text { verdes }\end{array}$ & $\begin{array}{l}\text { antese- } \\
\text { espigam. }\end{array}$ \\
\hline Repetição & 2 & 30.212 & 2,7 & 10 & 60 & 2 & 342.350 & 0,09 & 141 \\
\hline Hibrido & 2 & $21.226 .127^{*}$ & $8,2^{*}$ & $2278^{*}$ & $2555^{*}$ & 2 & $7.402 .846^{*}$ & $37,4^{*}$ & $513^{*}$ \\
\hline Resíduo (a) & 4 & 3.736 .240 & 0,9 & 12 & 143 & 4 & 815.942 & 0,22 & 107 \\
\hline Densidade & 3 & $9.503 .571^{*}$ & $19,0^{*}$ & 132 & 78 & 3 & $18.485 .735^{*}$ & $2,09^{*}$ & $132^{*}$ \\
\hline $\begin{array}{l}\text { Híbrido } x \\
\text { Densidade }\end{array}$ & 6 & $2.226 .697^{*}$ & 1,7 & 17 & 278 & 6 & 208.677 & 0,23 & $115^{*}$ \\
\hline Resíduo (b) & 18 & 359.902 & 1,1 & 20 & 171 & 18 & 141.543 & 0,15 & 27 \\
\hline Desfolha & 1 & $451.561 .352^{*}$ & 0,08 & $199^{*}$ & $11.572^{*}$ & - & - & - & - \\
\hline $\begin{array}{l}\text { Híbrido } x \\
\text { Desfolha }\end{array}$ & 2 & $1.489 .267^{*}$ & 1,97 & 43 & 79 & - & - & - & - \\
\hline $\begin{array}{l}\text { Densidade } x \\
\text { Desfolha }\end{array}$ & 3 & 603.421 & 1,56 & 44 & 247 & - & - & - & - \\
\hline $\begin{array}{l}\text { Hib x Dens } x \\
\text { Desfolha }\end{array}$ & 6 & 251.703 & 1,23 & 4 & 49 & - & - & - & - \\
\hline Resíduo (c) & 24 & 404.452 & 0,93 & 26 & 102 & - & - & - & - \\
\hline
\end{tabular}

*efeitos significativos a $5 \%(\mathrm{P}<0,05)$.

A resposta diferencial do rendimento de grãos dos híbridos testados ao incremento da população foi provavelmente motivada por características morfológicas, fisiológicas e fenológicas inerentes a cada genótipo. $O$ híbrido superprecoce P32R21 produziu menor número de folhas e menor área foliar no florescimento do que os materiais mais tardios, independentemente da densidade de semeadura (TABELA 2). O tipo de arquitetura de plantas que caracteriza os híbridos superprecoces pode contribuir para aumentar sua eficiência de uso da radiação solar quando semeados em altas densidades. A presença de menor número de folhas, de folhas mais eretas e de menor área foliar reduz o nível de interferência de uma planta sobre a outra, propiciando benefícios ao rendimento com a utilização de maior número de indivíduos por área (Tollenaar et al., 1997).

A menor interferência entre os indivíduos da população pode permitir um desenvolvimento mais sincronizado das inflorescências masculina e feminina. Neste sentido, o intervalo entre antese e espigamento do híbrido superprecoce foi pouco afetado pela densidade de semeadura (Figura 2). Por outro lado, este intervalo foi significativamente maior pelo incremento na população no híbrido tardio. Tais dados demonstram que a dominância apical e a natureza protândrica da planta de milho foram mais intensas com o aumento da população no híbrido tardio. Como o milho é uma planta cujo período de liberação de grãos de pólen é curto e definido e a coincidência entre antese e espigamento é fundamental para a polinização (Sangoi \& Salvador, 1998), pode-se inferir que o uso de populações elevadas trouxe maior comprometimento à fertilização dos materiais mais exigentes em UC para florescimento.

Os máximos rendimentos registrados com os híbridos P32R21 e Premium foram obtidos com a utilização de densidades superiores às recomendadas

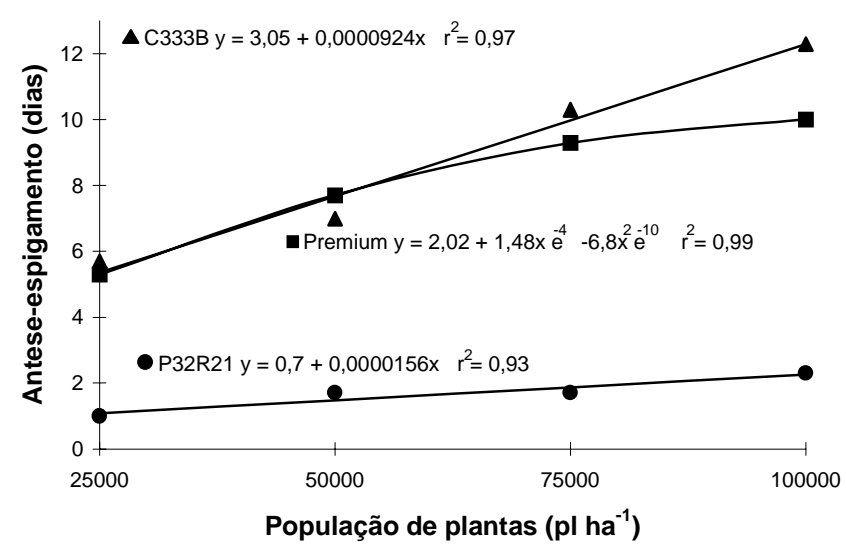

Figura 2 - Efeito da população sobre a duração do intervalo anteseespigamento de híbridos de milho de ciclos contrastantes, Lages, Sc, 1999/2000.

pelas empresas responsáveis por estes materiais (situadas entre 50.000 e 60.000 plantas por hectare). Esta discrepância pode ser explicada pela excelente fertilidade do solo da área experimental e pela regularidade da precipitação pluviométrica durante o ciclo da cultura. Quanto mais favoráveis forem as condições edafoclimáticas de uma região, maior será a população necessária para maximizar o rendimento de grãos (Peixoto et al., 1997; Sangoi, 2000). As características prevalecentes nos planaltos do sul do Brasil também contribuem para aumentar a resposta do milho à densidade de semeadura. As temperaturas atmosféricas mais baixas registradas especialmente a noite em regiões de altitude restringem o crescimento vegetativo, em comparação com regiões mais quentes do país (Sangoi, 1993). Este menor crescimento da planta pode ser compensado com a utilização de maior número de plantas por unidade de área, desde que se tenha condições favoráveis de clima e solo para tanto (Almeida et al., 2000). 
Contudo, deve-se ressaltar que o incremento na população de plantas reduziu o diâmetro de colmo, aumentando a percentagem de plantas acamadas e quebradas, a qual foi mais alta no híbrido superprecoce (TABELA 3). Portanto, a utilização de estandes muito adensados pode ser problemática, mesmo para híbridos que respondam em produtividade, devido a menor sustentabilidade da planta e a maior incidência de grãos ardidos (Molin, 2000; Sangoi et al., 2000).

Não foi constatada uma relação direta entre precocidade e suscetibilidade do material genético à desfolha. Os híbridos menos exigentes em UC foram mais produtivos do que o material mais tardio tanto nas parcelas em que 0 aparato fotossintético da planta foi mantido intacto quanto naquelas em que se removeu metade das folhas verdes na antese (TABELA 4). Após a desfolha, a área foliar remanescente do híbrido C333B foi 38\% superior a do híbrido P32R21 (TABELA 2). Contudo, a produtividade do genótipo tardio foi $16 \%$ inferior a do genótipo superprecoce quando desfolhado, na média das quatro populações avaliadas (TABELA 4).

A inexistência de associação entre área foliar remanescente no florescimento e produtividade por área indica que somente a presença de maior quantidade de superfície foliar fotossinteticamente ativa durante 0 período de enchimento de grãos não é suficiente para garantir rendimentos superiores. Há necessidade de que a magnitude das fontes prioritárias de produção de fotoassimilados seja acompanhada pela alta capacidade de demanda da inflorescência feminina da planta (Magalhães et al., 1995; Fancelli \& Dourado-Neto, 2000). Assim, para o híbrido tardio o fator limitante para a produção de grãos parece estar relacionado com a habilidade da planta de mobilizar e armazenar produtos fotossintetizados nos grãos e não com a capacidade da planta de produzir metabólitos. Esta hipótese é reforçada pelos menores valores de índice de colheita apresentados pelo híbrido $\mathrm{C} 333 \mathrm{~B}$, em relação aos genótipos mais precoces (TABELA 2), denotando menor aptidão deste material de alocar massa seca nas estruturas de interesse econômico.

Os dados das TABELAS 2 e 4 também demonstram que, havendo um dreno forte, é possível alcançar rendimentos satisfatórios, mesmo com área foliar reduzida, mediante a redistribuição de assimilados acumulados em outros órgãos da planta. Neste sentido, os colmos são estruturas moduladoras de grande importância para a definição do rendimento de grãos quando as folhas sofrem algum tipo de prejuízo na fase reprodutiva da cultura (Rajcan \& Tollenaar, 1999). Assim, - colmo pode atuar como órgão equilibrador da limitação de fonte, promovendo a remobilização dos carboidratos de reserva armazenados até o início do enchimento de grãos (Ruget, 1993; Uhart \& Andrade, 1995).
TABELA 2 - Características morfológicas de híbridos de milho de ciclos contrastantes, na média de quatro densidades de semeadura $(25.000,50.000$, 75.000 e $100.000 \mathrm{pl} \mathrm{ha}^{-1}$ ) Lages, SC, 1999/2000.

\begin{tabular}{|c|c|c|c|}
\hline $\begin{array}{c}\text { Característica } \\
\text { Agronômica }\end{array}$ & $\begin{array}{c}\text { P32R21 } \\
\text { (superprecoce) }\end{array}$ & $\begin{array}{l}\text { PREMIUM } \\
\text { (precoce) }\end{array}$ & $\begin{array}{l}\text { C333B } \\
\text { (tardio) }\end{array}$ \\
\hline Folhas tota is $\left(n^{\circ}\right)$ & $20,7^{*} \mathrm{C}$ & $21,9 \mathrm{~b}$ & $24,2 \mathrm{a}$ \\
\hline $\begin{array}{l}\text { Folhas verdes na } \\
\text { antese }\left(n^{\circ}\right)\end{array}$ & $14,2 \mathrm{~b}$ & $14,7 \mathrm{~b}$ & $16,7 \mathrm{a}$ \\
\hline $\begin{array}{l}\text { Área foliar total na } \\
\text { antese }\left(\mathrm{cm}^{2}\right)\end{array}$ & $7837 \mathrm{c}$ & $8487 b$ & $9534 a$ \\
\hline $\begin{array}{l}\text { Área foliar } \\
\text { remanescente }\left(\mathrm{cm}^{2}\right)\end{array}$ & $2744 b$ & $3548 a$ & $3800 a$ \\
\hline $\begin{array}{l}\text { Índice de } \\
\text { colheita(\%) }\end{array}$ & $55,1 \mathrm{a}$ & $47,1 \mathrm{~b}$ & $35,7 \mathrm{c}$ \\
\hline $\begin{array}{l}\text { Índice de } \\
\text { remobilização (\%) }\end{array}$ & $46,0 \mathrm{a}$ & $28,9 \mathrm{~b}$ & $27,4 \mathrm{~b}$ \\
\hline
\end{tabular}

*Médias seguidas de mesma letra minúscula na linha não diferem significativamente pelo teste de Duncan, a 5\%.

TABELA 3 - Efeito da população de plantas e do material sobre o diâmetro de colmo, percentagem de plantas acamadas e quebradas de milho, Lages SC, 1999/2000.

\begin{tabular}{ccc}
\hline Hỉbrido & Diâmetro de colmo & $\begin{array}{c}\text { Plantas acamadas e } \\
\text { quebradas }\end{array}$ \\
\hline P 32R21 & $\mathrm{mm}$ & $\%$ \\
Premium & $20,3^{* 1} \mathrm{~b}$ & $8,4 \mathrm{a}$ \\
C333B & $22,3 \mathrm{a}$ & $4,1 \mathrm{~b}$ \\
$\begin{array}{c}\text { Densidade } \\
\text { pl ha-1 }\end{array}$ & $\begin{array}{c}\text { Diâmetro de colmo } \\
\text { 25.000 }\end{array}$ & $\begin{array}{c}\text { Plantas acamadas e } \\
\text { quebradas } \%\end{array}$ \\
50.000 & $26,9^{2} \mathrm{a}$ & $0,5 \mathrm{c}$ \\
75.000 & $22,4 \mathrm{~b}$ & $3,6 \mathrm{~b}$ \\
100.000 & $19,8 \mathrm{c}$ & $5,9 \mathrm{~b}$ \\
\hline
\end{tabular}

*Médias seguidas de mesma letra minúscula na coluna, para cada efeito simples do fator sobre a variável, não diferem significativamente pelo teste de Duncan, a $5 \%$

${ }^{1}$-Médias de quatro densidades e dois níveis de desfolha.

${ }^{2}$-Médias de três híbridos e dois níveis de desfolha

TABELA 4 - Efeito da desfolha no rendimento de grãos de híbridos de milho de ciclos contrastantes, na média de quatro densidades de semeadura $\left(25.000,50.000,75.000\right.$ e $\left.100.000 \mathrm{pl} \mathrm{ha}^{-1}\right)$, Lages, SC, 1999/2000.

\begin{tabular}{lcc}
\hline \multicolumn{1}{c}{ Hîbrido } & Área Foliar Intacta & Desfolhado \\
\hline $\begin{array}{l}\text { P32R21 } \\
\text { (superprecoce) }\end{array}$ & A $11.734^{*}$ a & A $6.316 \mathrm{~b}$ \\
$\begin{array}{l}\text { PREMIUM } \\
\text { (precoce) }\end{array}$ & A $11.881 \mathrm{a}$ & A $6.728 \mathrm{~b}$ \\
$\begin{array}{l}\text { C333B } \\
\text { (tardio) }\end{array}$ & B $9.781 \mathrm{a}$ & B $5.326 \mathrm{~b}$ \\
\hline
\end{tabular}

*Médias antecedidas de mesma letra maiúscula na coluna e sucedidas por mesma letra minúscula na linha, não diferem significativamente pelo teste de Duncan, a $5 \%$. 
O índice de remobilização do híbrido superprecoce foi significativamente superior ao dos híbridos mais tardios (TABELA 2). Esta característica demonstra que este material apresentou maior capacidade de armazenar e redirecionar carboidratos do colmo para os grãos durante o enchimento dos mesmos, possivelmente em função da maior força de dreno do genótipo. Assim, a maior remobilização das reservas acumuladas no colmo do material superprecoce compensou a sua menor área foliar, garantindo maior índice de colheita e maior rendimento de grãos, em relação ao híbrido tardio (TABELAS 2 e 4). Por outro lado, o maior direcionamento de fotoassimilados do colmo para os grãos do híbrido superprecoce fragilizou a estrutura de sustentação da planta, aumentando a sua suscetibilidade a quebra e acamamento quando a atividade das folhas foi limitada pelo uso de alta densidade ou pela desfolha (TABELA 3).

$O$ rendimento obtido com os híbridos testados nas parcelas desfolhadas oscilou entre entre $53,8 \%$ e $56,7 \%$ dos valores registrados quando o aparato fotossintético foi mantido intacto (TABELA 4). Por outro lado, a remoção de metade das folhas verdes na antese fez com que as parcelas desfolhadas apresentassem uma área foliar remanescente que variou entre $35 \%$ e $41,8 \%$ dos valores característicos de cada híbrido (TABELA 2). Portanto, a redução da área foliar foi percentualmente mais drástica do que a redução no rendimento de grãos. Isto confirma a atuação do colmo como órgão modulador da restrição imposta às folhas, atenuando os prejuízos ocasionados pela desfolha ao rendimento de grãos, principalmente no híbrido superprecoce.

\section{REFERÊNCIAS BIBLIOGRÁFICAS}

ALMEIDA, M.L.; MEROTTO JR.; A.; SANGOI, L.; ENDER, M.; GUIDOLIN, A.F. Incremento na densidade de plantas: uma alternativa para aumentar o rendimento de grãos de milho em regiões de curta estação estival de crescimento. Revista Ciência Rural, v.30, p.23-29, 2000.

COMISSÃO DE FERTILIDADE DO SOLO - RS/SC. Recomendações de adubação e calagem para os estados do Rio Grande do Sul e Santa Catarina. 3.ed. Passo Fundo: SBCS-Núcleo Regional Sul; EMBRAPA,CNPT, 1995. 223p.

EMBRAPA.Centro Nacional de Pesquisa de Solos. Sistema brasileiro de classificação de solos. Rio de Janeiro: Embrapa, CNPS, 1999. 412p.

EPAGRI. Avaliação de cultivares para o estado de Santa Catarina 2000/2001. Florianópolis: 2000. 152p. (Boletim Técnico, 107)

FANCELLI, A.L.; DOURADO-NETO, D. Fisiologia da produção e aspectos básicos de manejo para alto rendimento. In: SANDNI, I.E.; FANCELLI, A.L. Milho: estratégias de manejo para a Região Sul. Guarapuava: Fundação Agrária de Pesquisa Agropecuária, 2000. cap.7, p.103-115.

FEPAGRO/EMATER/FECOTRIGO. Recomendações técnicas para a cultura do milho no Estado do Rio Grande do Sul. Porto Alegre: 1998. 148p. (Boletim Técnico, 5)
FISHER, K.S.; PALMER, A.F.E. Tropical maize. In: GOLSDWORTHY, P.R.; FISHER, N.M. (Ed.) The physiology of tropical field crops. New York: John Wiley \& Sons, 1984. cap.6, p.213-248.

MAGALHÃES, P.C.; DURÃES, F.O.M; PAIVA, E. Fisiologia da planta de milho. Sete Lagoas: Embrapa, 1995. 27p. (Circular Técnica, 20)

MOLIN, R. Ocorrência e prevenção de grãos ardidos e micotoxinas na cultura do milho. In: SANDNI, I.E.; FANCELLI, A.L. Milho: estratégias de manejo para a Região Sul. Guarapuava: Fundação Agrária de Pesquisa Agropecuária, 2000. cap.8, p.117-130.

MUNDSTOCK, C.M. Bases fisiológicas para aumentar o rendimento de milho no sul do Brasil. In: REUNIÃO TÉCNICA CATARINENSE DE MILHO E FEIJÃO, 2., Lages, 1999. Resumos. Lages: Universidade do Estado de Santa Catarina, 1999. p.31-33.

OLSON, R.A.; SANDERS, D.H. Maize production. In: SPRAGUE, G.F. DUDLEY, J.W. Corn and corn improvement. Madison: ASA, 1988. cap.11, p.639-686.

PEIXOTO, C.M.; SILVA, P.R.F.da; REZER, F.; CARMONA, R.C. Produtividade de híbridos de milho em função da densidade de plantas, em dois níveis de manejo da água e da adubação. Pesquisa Agropecuária Gaúcha, v.3, p.63-71, 1997.

RAJCAN, I.; TOLLENAAR, M. Source:sink ratio and leaf senescence in maize: I. Dry matter accumulation and partitioning during grain filling. Field Crops Research, v.60, p.245-253, 1999.

RITCHIE, S.W.; HANWAY, J.J. How a corn plant develops. Ames: lowa State University of Science and Technology, 1993. 26p. (Special Report, 48).

RUGET, F. Contribution of storage reserves during grain filling of maize in northern european conditions. Maydica, v.38, p.51-59, 1993.

SANGOI, L. Aptidão dos campos de Lages (SC) para produção de milho em diferentes épocas de semeadura. Pesquisa Agropecuária Brasileira, v.28, p.51-63, 1993.

SANGOI, L. Understanding plant density effects on maize growth and development: an important issue to maximize grain yield. Ciência Rural, v.31, n.2, 2001.

SANGOI, L.; SALVADOR, R.J. Effect of maize detasseling on grain yield tolerance to high plant density and drought stress. Pesquisa Agropecuária Brasileira, v.33, p.677-684, 1998.

SANGOI, L.; ENDER, M.; GUIDOLIN, A.F.; BOGO, A.; KOTHE, D.M. Incidência e severidade de doenças de quatro híbridos de milho cultivados com diferentes densidades de plantas. Ciência Rural, v.30, p.17-21, 2000.

SILVA, P.R.F. da. Densidade e arranjo de plantas em milho. In: CONGRESSO NACIONAL DE MILHO E SORGO, 19., Porto Alegre, 1992. Conferências. Porto Alegre: Secretaria da Agricultura; CIENTEC; ABMS, 1992. p.291-294.

TOLLENAAR, M. Is low plant density a stress in maize? Maydica, v.37, p.305-311, 1992.

TOLLENAAR, M.; DWYER, L.M. Physiology of maize. In: SMITH, D.L.; HAMEL, C. (Ed.) Crop yield, physiology and processes. Berlin: Springer-Verlag, 1999. cap.5, p.169-201.

TOLLENAAR, M.; AGUILERA, A.; NISSANKA, S.P. Grain yield is reduced more by weed interference in an old than in a new maize hybrid. Agronomy Journal, v.89, p.239-246, 1997.

UHART, S.A.; ANDRADE, F.H. Nitrogen and carbon accumulation and remobilization during grain filling in maize under different source and sink ratios. Crop Science, v.35, p.183-190, 1995.

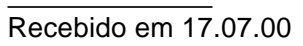

